\title{
La Expresión Literaria de América
}

$\mathbf{E}^{\mathrm{s}}$ S significativo que en este Tercer Congreso Internacional de Catedráticos de Literatura Iberoamericana se renueve el tema que me ocupa en estos instantes: la expresión literaria de América. ¿Quién pudo preocuparse de este asunto en los días coloniales? La tradición literaria recibida de España, dentro de la cual se vivía cómodamente, tenía una respuesta a todas las inquietudes del escritor, si es que alguna asaltaba su espíritu. Fué preciso que la revolución de la independencia cortara los lazos de sujeción entre la metrópoli y sus provincias de Ultramar para que el escritor comenzara a interrogarse. Si había logrado la emancipación política, ¿no podía aspirar a la intelectual? Los modelos literarios en los cuales habían adorado los padres, ¿podían satisfacer a los hijos y a los nietos? ¿O había derecho a exigir que nuevos modelos ocuparan el lugar de los antiguos? El arte de escribir debía sufrir una conmoción profunda de aquellos hechos, y en realidad la sufrió.

Cuando las provincias americanas sacudieron la tutela peninsular, la última nota recibida sonaba ya a difunta. El clasicismo de fines del siglo XVIII no podía satisfacer a hombres que, aunque nacidos en ese siglo, se sentían de pleno derecho hijos del siguiente. Y por lo demás, ¿qué podía haber de común entre ambas centurias? En medio de ellas se interponía la lucha, y no es indispensable decir cuántos conceptos no directamente comprometidos en ella se adscribieron a la rebelión del criollo. Se habló entonces de tres siglos de esclavitud, y se creyó fácil retornar a las fuentes pristinas de lo americano en virtud de consideraciones tan elevadas como ajenas del arte literario mismo. 
La revolución de la independencia se hizo en nombre de principios que no habían adquirido en España el carácter urgente que alcanzaron en América. España no derribó a su Rey. Fué un invasor extranjero quien lo depuso, y fueron las ansias de dominación universal de ese mismo invasor las que mantuvieron a la península en la agitación que no había de llevar a otra cosa que a una reacción completa. Los primeros insurgentes - si es posible llamarlos así- confesaron el carácter provisional de su intervención en la cosa pública, al decir que asumían el mando en ausencia del monarca legítimo y sólo mientras él estuviera impedido de llevat a cabo la misión que había recibido de Dios y que heredaba de sus antepasados. Fueron otros, más audaces e inquietos, los que, deslizados hasta los consejos de gobierno, fueron denunciando poco a poco, y a veces en medio de timideces que revelaban la falta de preparación con que afrontarían las tareas de su nuevo papel, el ánimo de romper con la metrópoli. Bien se sabe que entre alternativas de avance y de retroceso la revolución en definitiva ganó los corazones de todos los americanos y dió nacimiento a las patrias libres que ahora existen.

Estos hechos ajenos de la literatura sirven para explicar lo que más tarde vino. Embriagados los hombres de la primera generación revolucionaria con la ideología en cuyo nombre habían librado la lucha y, sobre todo, con el buen éxito que coronó su iniciativa, fácil les fué concebir que al emanciparse de España iban a poder prescindir enteramente del paso colonial. Esta vana ilusión fué la primera que hizo nacer la necesidad de una expresión literaria propia en el continente americano.

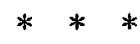

El poeta argentino Esteban Echeverría, que había vivido en Europa, fué uno de los primeros que dieron forma a esta inquietud al examinar la poesía de su tiempo y al proponerse, con originalidad y audacia muy propias de su carácter romántico, abrir para la que se cultivara en tierras americanas un horizonte que fuese nuevo. La primera de sus observaciones tiene alcance sólo de escuela. El poeta, en efecto, afirma: 
El romanticismo es la poesía moderna que fiel a las leyes esenciales del arte no imita, ni copia, sino que busca sus tipos y colores, sus pensamientos y formas en sí mismo, en su religión, en el mundo que lo rodea y produce con ellos obras bellas, originales. En este sentido todos los poetas verdaderamente románticos son originales y se confunden con los clásicos antiguos, pues recibieron este nombre por cuanto se considetaron como modelos de perfección, o tipos originales dignos de ser imitados.

$Y$ decimos que estas digresiones tienen sabor de escuela porque el poeta argentino reduce sus observaciones a la poesía romántica. A ella le pide ser, al mismo tiempo, moderna y "fiel a las leyes esenciales del arte", con el agregado de que por ser fiel a ellas "no imita, ni copia". Pero la "ley esencial" del arte, que acaso aconseje como dice Echeverría no copiar ni imitar, aconseja en cambio observar el mundo que rodea al poeta.

Entonces venimos a parar en lo que podría llamarse el segundo principio de Echeverría. ¿Qué rodea al poeta americano? La naturaleza del nuevo mundo. Obvio es entonces que ese poeta encuentre en ella la originalidad que es la meta final de sus empeños. Pero es mejor que veamos cómo desenvuelve su pensamiento:

El espíritu del siglo lleva hoy a las naciones a emanciparse, a gozar de la Independencia, no sólo política sino filosófica y literaria; a vincular su gloria no sólo en libertad, en riqueza y en poder, sino en el libre y espontáneo ejerçicio de sus facultades morales $y$ de consiguiente en la originalidad de sus artistas. Nosotros tenemos derecho para ambicionar lo mismo y nos hallamos en la mejor condición para hacetlo. Nuestra cultura empieza: hemos sentido sólo de rechazo el influjo del clasicismo; quizá algunos lo profesan, pero sin séquito, porque no puede existir opinión pública racional sobre materia de gusto en donde la literatura está en embrión y no es ella una potencia social. Sin embargo, debemos antes de poner mano a la obra, saber a qué atenernos en materia de doctrinas literarias y profesar aquellas que sean más conformes a nuestra condición y estén a la altura de la ilustración del siglo y nos trillen el camino de una literatura fecunda y original, pues en suma, como dice Hugo, el Romanticismo no es más que el Liberalismo en literatura. 1

En esta digresión no nos conviene pormenorizar demasiado: el pensamiento del poeta anda a saltos y no es tan claro como habría sido de desear. Lo que más interesa es aquella sentencia aislada, 
pero perfectamente nítida en la expresión, que dice: "Nuestra cultura empieza..." Echeverría probó aquí tal vez por la vez primera que el pensamiento americano seguiría desde sus días hasta los nuestros el camino de la soberbia. Cuando el poeta argentino dice "nuestra cultura" no puede referirse a otra que a la de su medio social y familiar, a la que él compartía con todos los hombres de su tiempo y de su país, formados en condiciones parecidas a las suyas. $Y$ bien: el poeta no era otra cosa que un español, aun cuando no hubiese nacido en la península sino en una de las provincias ultramarinas, y como tal español era un europeo. ¿ Puede un europeo del siglo XIX decir que su cultura empieza? Para decirlo es preciso que ignore su origen y pretenda entonces no ser español y europeo, sino americano, o que ignore el legado cultural del cual es depositario por ser español y europeo. Sin decirlo, el poeta se revela como precursor del indigenismo que más tarde, siempre por el camino de la soberbia, ha tendido su trampa al incauto americano.

$Y$ he aquí, pues, que los organizadores de este certamen plantean la proposición cardinal que por mucho tiempo sin duda va a dividir a los escritores de este continente. ¿Podemos aspirar a una expresión literaria que nos sea propia? Creo que sólo plantear la pregunta equivale a responderla. Nos movemos dentro del ámbito de una cultura que no hemos formado. Somos depositarios de un legado espiritual que viene de muy lejos y en el cual no parece lícito introducir otros cambios que los que nos permiten el estado de nuestro avance y las fuerzas que hemos venido mostrando en el camino.

E1 propio Echeverría, sin embargo, nos hará ver en otro de sus fragmentos la segunda cara de la medalla, la que no apareció en sus palabras anteriores. En septiembre de 1837, al inaugurar un salón literario, el poeta argentino dijo lo sigtiiente, que parece calculado para proponerse las mismas dificultades que nosotros ya expresamos :

Todo el saber e ilustración que poseemos no nos pertenece; es un fondo, si se quiere, pero no constituye una riqueza real, adquirida con el sudor de nuestro rostro, sino debida a la generosidad extranjera. Es una vestidura hecha de pedazos diferentes y de distintó color, con la cual apenas podemos cubrir nuestra miserable desnudez. 2 
No hay más, pero acaso lo que haya sea bastante. No hemos creado esta cultura: la hemos recibido en préstamo. ¿Qué base puede tener entonces la pretensión de hacer la independencia intelectual una vez lograda la política, y sólo porque se ha logrado ya ésta? La soberbia, empero, habrá de revivir una y muchas veces más, y después de cien años de lo que escribió Echeverría no pocos escritores americanos se sentirían tentados de suscribir las primeras proposiciones que de él hemos citado, aunque acaso no la última, por la muy visible contradicción que hay entre ellas.

$$
\text { * * * }
$$

El día 3 de mayo de 1842 don José Victorino Lastarria, escritor chileno, pronunciaba un discurso famoso en ocasión de incorporarse como director de la Sociedad Literaria formada por los alumnos del Instituto Nacional de Santiago. Y este discurso, que es la portada de nuestra literatura moderna, señalaba una nueva cima de la soberbia americana que nos está preocupando en estas notas.

Para examinar con detenimiento las principales ideas que aparecen en ese discurso, nos vamos a permitir poner en orden diverso al del original las proposiciones cardinales.

1. "No hay sobre la tierra -dice Lastarria- pueblos que tengan como los americanos una necesidad más imperiosa de ser originales en su literatura, porque todas sus modificaciones les son peculiares y nada tienen de común con las que constituyen la originalidad del Viejo Mundo." ¿Verdad o mentira? Mentira, sin duda alguna. Lo original y nuevo en el continente colombiano no es el conjunto de modificaciones que han sufrido los pueblos que lo componen, sino acaso la naturaleza dentro de la cual estos pueblos desarrollan su existencia. Los hombres son unos mismos, cualquiera que sea el escenario físico que los rodea, y ni siquiera cambian sensiblemente con el paso del tiempo.

Cuenta Anatole France que un rey quiso conocer la historia de la humanidad y encargó a un sabio historiador que le compusiera una obra para leerla de corrido. El sabio estudió, investigó, trabajó con tesón incomparable, y presentó a su señor, como resultado de sus pesquisas, varios ingentes volúmenes. Pero su señor no tenía tiempo para leer tantos libros, ya que no en balde había ido enve- 
jeciendo al mismo compás que su escribiente, y le pidió un resumen. $\mathrm{Y}$ de resumen en resumen, a medida que apretaban los años del rey y de su servidor, el sabio llegó a concretar la historia de la humanidad en una sola sentencia: "Nacieron, sufrieron y murieron." Esta pequeña ilustración puede servir de reactivo a la frase de Lastarria, para reducirla a su verdadero alcance. Literariamente hablando, la proposición del discurso que acabamos de señalar en el número 1 no vale nada ni quiere decir nada.

2. Pero el escritor chileno tenía entre pecho y espalda un enemigo al cual dispara sus dardos: el régimen colonial de España en América. Al escribir to que se ha leído más arriba pensaba no en otra cosa que en introducir en sus oyentes la persuasión de que nada quedaba de común, política y socialmente consideradas las cosas, entre la América emancipada y la metrópoli española que la había sojuzgado durante tres siglos. Este pensamiento queda declarado por el autor del discurso en otro pasaje:

Apenas ha amanecido para nosotros el 18 de septiembre de 1810, estamos en la alborada de nuestra vida social, $y$ no hay un recuerdo $\tan$ solo que nos halague, ni un lazo que nos una a lo pasado, antes de aquel dia. Durante la colonia no rayó jamás la luz de la civilización en nuestro suelo.

Aquí ya se nos muestra de resalte lo que Lastarria quería decir con la proposición anterior. El objetivo final de su discurso era producir horror por el régimen colonial de España, aun cuando para ello fuese necesario tergiversar las más obvias verdades. En el párrafo transcrito queda todo en claro. Para Lastarria no había brillado la luz de la civilización en América durante el régimen español, y esa era debía quedar, por lo tanto, olvidada lo antes posible por los americanos de su tiempo y de los venideros. Había sido una época de oscurantismo, de opresión, de barbarie; durante ella se habían pisoteado los derechos de los pueblos, desposeído a los naturales de su propiedad, impuéstoles instituciones que no eran de su acomodo y anulado, en fin, la voluntad libérrima en cuyo ejercicio se habían unido hasta el día en que los españoles pusieron su planta en la tierra americana. La misión de los jóvenes que entonces le escuchaban no era ni podía ser otra que restablecer las cosas a la pristinidad que tuvieron antes del 12 de octubre de 1492. 
3. Esto implica proseguir la revolución de la Independencia hasta retrotraer las cosas al estado en que se hallaban antes de la conquista etropea. A cualquier hombre que tuviera la cabeza sobre los hombros, el programa debía asustarlo. Lastarria, como ideólogo impenitente que era, no temía decirlo y lo dijo:

Esa literatura (la española) no debe ser la nuestra, porque al cortar las cadenas enmohecidas que nos ligaran a la Península, comenzó a tomar otro tinte muy diverso nuestra nacionalidad... Es necesario que desarrollemos nuestra revolución y la sigamos en sus tendencias civilizadoras, en esa marcha peculiar que le da un carácter de todo punto contrario al que nos dictan el gusto, los principios y las tendencias de aquella literatura.

Llevado por el viento impetuoso de la ideología, Lastarria no divisa que si "desarrollamos la revolución" volveremos a la barbarie pre-colombiana, como ha sucedido en dondequiera que se hayan querido romper las "cadenas enmohecidas" y los demás símbolos de la hispanidad.

4. En realidad, su pensamiento no es tan radical y propende más bien a la transacción. Decimos èsto porque, a corta distancia de la enormidad que le acabamos de ver sostener, leemos algo que tiene grande importancia en sus labios. Al expresarse sobre la literatura de "nuestros conquistadores" no debe creerse que "mira en menos su hermoso y abundante idioma”, y agrega: "‘ Ah, no!, éste fué uno de los pocos dones preciosos que nos hicieron sin pensarlo." ¿Cómo sin pensarlo? Si los españoles no hubiesen fundado escuelas y universidades a poco de instalarse en América, cabría alguna duda al respecto; pero las fundaron, y en ellas alcanzó a reflejarse tan nítidamente el pensamiento de la España de ese tiempo como era permitido, dadas las distancias y las demás dificultades que se interponían entre ambos continentes. Los españoles quisieron que se hablara en América su lengua, y para ello no sólo establecieron aquellas escuelas y universidades sino también otras, los "colegios de naturales", que no tenían tarea más principal que enseñar español a los aborígenes.

5. Finalmente -y aquí vemos lo que más nos interesa en este momento-, Lastarria aconseja cultivar una literatura propia: 
... muy poco tenemos que imitar: nuestra literatura debe sernos exclusivamente propia, debe ser enteramente nacional.

El consejo, o mandato, es engañoso. No poseemos una lengua que hayamos formado nosotros, como reconoce paladinamente el propio Lastarria, ni nuestras costumbres son otra cosa que las de todos los hombres civilizados de Occidente, herederos de la cultura grecolatina, con las mutaciones más de apariencia que de fondo que corresponden a medios en formación y que procuran, siempre con extraordinario atraso, tomar la marcha que la cultura lleva en las naciones que nos sirven de modelo y de guía: España en el uso de la lengua, Francia en el terreno de las ideas. ¿Cómo podemos, en tales condiciones, hablar de una literatura "exclusivamente propia"? Queda un solo elemento que no ha sido comprendido en el escrutinio: la naturaleza física de América. Ella es en suma el único ingrediente literario - por decirlo así- que poseemos de verdad en la forma exclusiva que Lastarria quiere. Hablando de ella, copiando sus formas, inspirándonos en sus bellezas, haremos una literatura americana hasta donde sea posible juntar estos dos términos. Pero cabe reconocer que la naturaleza es sólo un elemento decorativo en el conjunto de la literatura, ya que lo que en ésta más vale son los sentimientos, las emociones, los caracteres de los hombres y las situaciones que con ellos se plantean. Es concebible un libro que no pretenda otra cosa que describir la naturaleza americana, y seguramente la literatura en él contenida puede ser bellísima y hasta sublime; pero lo más frecuente será que los escritores de este continente quieran poner en acción al hombre, en medio de la naturaleza americana o fuera de ella, y desde ese mismo momento se habrá evadido del único elemento "exclusivamente propio" que le es dado abarcar al escritor de este Continente. Los sentimientos, los caracteres serán universales o poco menos, y la lengua en que éstos y el escritor mismo se expresan no será otra cosa que la lengua española, por cuyo esplendor el mismo Lastarria quiebra lanzas en el discurso que estamos comentando.

Por estos dos pequeños ejemplos que hemos proporcionado, ha podido verse que la inquisición sobre los orígenes efectivos y los 
alcances finales de la literatura americana que pretenda tal nombre, no es nueva. Hace ya, en efecto, más de un siglo que estos problemas ocuparon a dos de los pensadores literarios más egregios de que pueden enorgullecerse las naciones del Sur: Esteban Echeverría y José Victorino Lastarria. Ambos han argumentado en forma parecida y ambos aparecen dominados por una exclusiva preocupación: la de dar un contenido netamente americano al arte de escribir; ambos también han partido para ello de un supuesto que nos parece abiertamente incompatible con las enseñanzas obvias de la historia, el de que la cultura española no podía tener una sucesión directa en América. Echeverría confesaba que la cultura americana no había nacido en este suelo virgen; Lastarria, ideólogo más impermeable que el poeta argentino a la realidad de las cosas, no se pronunció claramente sobre si esa cultura es propia o prestada, y cuando le fué preciso decir algo sobre el punto, manifestó sin ambages "su convencimiento de que los americanos debían procurar la formación de una cultura que fuese el substractum del ambiente nuevo, así social como político, que se ha formado en América.

La polémica ha seguido más tarde desarrollándose en todas las naciones hispanoamericanas, y sigue dividiendo a los escritores. Para que las deliberaciones de este Congreso sean fructuosas, es deseable que las personas a quienes se ha encargado dilucidar tales temas presenten conclusiones o propongan síntesis a las cuales puedan asentir, por lo menos en parte, los delegados. Temo que en e1 presente caso sea difícil conseguir la unanimidad.

Mi pensamiento al respecto se aparta no poco de los cauces que sigue la obra de los escritores americanistas o criollistas o indigenistas, que son algunos de los nombres con que se han caracterizado estas tendencias. La literatura es un fenómeno preferentemente espiritual, y por serlo le son aplicables las leyes generales de la vida del espíritu, que no reconocen divisiones ni encasillamientos meramente regionales. Si haciendo abstracción de los mil motivos que tenemos para estimar así las cosas, dejáramos a la literatura fuera de estas leyes de alcance universal y la creyéramos susceptible de aceptar subdivisiones, deberíamos formular al mismo tiempo leyes para que las producciones del ingenio humano se pudieran encasillar conforme a las fronteras políticas, o raciales, o religiosas, que separan a los hombres. Sólo provisionalmente, y para facilitar el estudio, 
podemos hablar de una novela chilena, de una poesía lírica mexicana, o colombiana, o argentina. Para la crítica literaria que busque las esencias y no se detenga sólo en los fenómenos más contingentes de la vida de las letras, no hay ni puede haber más que un escalafón, el de la genialidad en la creación, ni se concebiría que en virtud de consideraciones más o menos adventicias abdicara de sus prerrogativas que la hacen universal.

Afortunadamente hemos ido despejando en el camino algunas de las preocupaciones que otros tiempos embargaron el espíritu de nuestros predecesores. No tememos que el espíritu de España, indisolublemente unido a su lengua, corte el vuelo audaz de nuestra fantasía, ni creemos que pudiera convenir mejor a nuestras disposiciones para el ejercicio de las letras la imitación de modelos de otras lenguas. $Y$ no lo tememos en virtud precisamente de que nos conocemos mejor y de que poseemos mayor confianza en nuestras fuerzas propias. América está abierta a todos los vientos del espíritu, y los hombres cultos que la pueblan saben ya que no conviene cerrarse a piedra y lodo al influjo de ninguna corriente cultural. De todas ellas podrá entiquecerse el espíritu americano si en él imperan la discreción, el buen gusto, el tino y la simpatía. Haremos arte americano si preferimos que sea la naturaleza del Nuevo Mundo la que circunde nuestras creaciones, pero haremos arte universal porque el arte no puede ser otra cosa que universal desde el momento mismo en que sobre él imperan leyes que no reconocen limitación regional de ninguna especie, como que su ejercicio toca a las raíces de la persona humana y no se detiene sólo en los accidentes de tiempo y de región.

Raúl Silva Castro

1 Las citas corresponden al artículo títulado "Clasicismo y romanticismo", publicado en las Obtas completas de Echeverría, t. V, p. 97 para la primera, y pp. 99-100 para la segunda.

2 Obtas completas ya citadas, t. V, p. 329. 